\title{
Addressing the health advocate role in medical education
}

\author{
Suzanne Boroumand ${ }^{1 *}$ (D, Michael J. Stein ${ }^{2}$, Mohammad Jay ${ }^{1}$, Julia W. Shen ${ }^{1}$, Michael Hirsh ${ }^{1}$ and Shafik Dharamsi
}

\begin{abstract}
The health advocate role is an essential and underappreciated component of the CanMEDs competency framework. It is tied to the concept of social accountability and its application to medical schools for preparing future physicians who will work to ensure an equitable healthcare system. Student involvement in health advocacy throughout medical school can inspire a long-term commitment to address health disparities. The Social Medicine Network (SMN) provides an online platform for medical trainees to seek opportunities to address health disparities, with the goal of bridging the gap between the social determinants of health and clinical medicine. This online platform provides a list of health advocacy related opportunities for addressing issues that impede health equity, whether through research, community engagement, or clinical care.

First implemented at the University of British Columbia, the SMN has since expanded to other medical schools across Canada. At the University of Ottawa, the SMN is being used to augment didactic teachings of health advocacy and social accountability. This article reports on the development and application of the SMN as a resource for medical trainees seeking meaningful and actionable opportunities to enact their role as health advocates.
\end{abstract}

Keywords: Social determinants of health, Interprofessionalism, Advocacy, Medical education

\section{Background}

The Health Advocate role is a vital pillar of the CanMEDs competency framework, requiring future physicians to develop key capabilities that would enable them to address the social determinants of health and improve health outcomes at the level of the patient, the community, and the populations served. However, it has received an underwhelming response by Canadian medical educators, physicians, and students [1]. The effective integration of health advocacy related competencies into medical education remains a challenge [2-7]. Canadian physicians surveyed in 2012 indicated that health advocacy is perceived to be of lesser significance among the CanMEDs roles [8]. Similar findings were observed in European studies $[9,10]$. Some scholars believe that the lack of socioeconomic diversity in the medical school class demographic profile is partly to blame [6]. Others point out that medical education offers limited opportunities to work with socially disadvantaged and marginalized segments of the population, which is required to

\footnotetext{
* Correspondence: sboro014@uottawa.ca

${ }^{1}$ Faculty of Medicine, University of Ottawa, Ottawa, Ontario, Canada

Full list of author information is available at the end of the article
}

instrument the knowledge and skills necessary to be an effective health advocate $[1,6,9,11,12]$. Medical programs that do provide experiential and community service learning initiatives with a focus on health advocacy and the social determinants of health reported that these types of authentic learning activities are key to enabling students to gain a greater insight into how health advocacy can be applied $[13,14]$. Students are enabled to develop a greater appreciation of the root causes and subsequent effects of health disparities, and a greater sensitivity to the circumstances of people in society who are rendered vulnerable because of various socioeconomic factors that prevent them from protecting and preserving their well-being [15-19]. In response to the deficit, the Committee on the Accreditation of Canadian Medical Schools (CACMS) and the Liaison Committee on Medical Education (LCME) in the United States officially adopted a new accreditation standard requiring medical schools in North America to include servicelearning opportunities to medical students to address this gap.

At the health system-level, physicians are expected to work alongside communities to advocate for change that 
reflects principles of social accountability [11]. However, many physicians feel frustrated when faced with patients from complex socioeconomic backgrounds, expressing reluctance to engage in discussions around patients' social situations $[9,12]$. The low emphasis on health advocacy is likely multifactorial. For one, the health advocate role has been noted as difficult to teach and assess [1]. In addition, medical school admissions committees have habitually placed a higher value on students' academic scores, with little attention to their experience and understanding of social issues [15]. Furthermore, time constraints are a likely contributor to physicians avoiding discussions around the social causes leading to poor health outcomes [20]. Finally, the majority of medical training occurs in academic institutions, distant from community areas where some marginalized populations live [21].

To address these challenges, in 2013, a small group of medical students and residents at the University of British Columbia, with faculty support, established an online platform to assist medical trainees to seek out meaningful opportunities to enact the CanMEDS role of the health advocate [22]. The aim of this platform, named the Social Medicine Network (SMN), was to provide an online resource that would help students identify health providers and/or agencies whose work would enable them to bridge the learning gap between what they are taught about the social determinants of health and what to $d o$ to address the related health issues that subsequently arise. The online platform was subsequently adopted and adapted by the medical students at the University of Ottawa, and endorsed by the Canadian Federation of Medical Students. In this paper, we report on the development and components of SMN, while linking its role to experiential learning of advocacy.

\section{The Social Medicine Network (SMN)}

The Social Medicine Network is a web-based resource that lists clinical, service, and research related opportunities where medical trainees can gain practical knowledge and skills to address the social determinants of health and respond to health disparities that vulnerable populations may face [22]. Trainees are able to find and select clinical, community or research related opportunities that align with their own interests and commitments toward addressing issues that impede health equity. Opportunities are available in a wide range of areas: Addictions Health, Environmental Health, Health Education and Advocacy, Immigrant and Refugee Health, Indigenous Health, LGBTQ Health, Mental Health, Prison Health, Homelessness, and Women's Health. The website is maintained by a group of students who have both the technical ability to maintain it, and the commitment and inspiration to find and recruit organizations using templates listed in Additional file 1, that can provide the relevant clinical, service, and action research opportunities. Ideally, the opportunities ought to help trainees develop the skills necessary to becoming an effective health advocate. Once the organization has consented to providing students with a volunteer, research, or clinical placement opportunity, the contact information including the address, phone number, email address, and description of the opportunity and role provided by the organization is included on the website under each category. Medical trainees are then encouraged to contact the organizations by email or phone for opportunities they are interested in, and subsequently liaise with the organization's administrator to arrange for a start date. The organizations will then share with the trainees the protocols and actions necessary to get started with the process.

\section{Community engagement is key}

Effective health advocacy is perhaps more crucial today than ever before [23]. Traditional didactic methods of teaching are insufficient in fostering passion and skills for health advocacy. Akin to teaching clinical knowledge through bedside teaching, an effective way of teaching health advocacy is through community involvement that actively involves learners in the advocacy process [11]. According to a systematic review that analyzed 57 peerreviewed articles on service learning or communitybased education in US medical schools, educators found it easier to use community learning to teach complicated or abstract topics such as cultural competence, the social determinants of health, and professionalism, compared to traditional didactic methods [24-34]. Students who engaged in authentic, hands-on activities developed deeper insights and understanding of related issues and how to better address them [24-34]. Community engagement allows learners to observe and work to address health disparities first-hand, enhancing their understanding of the practical relevance of health advocacy, and fueling their passion for finding solutions to what may appear to be insurmountable issues $[3,11,16,17,35-40]$.

In a recent case study by the University of British Columbia (UBC), medical students investigated the impact of a community-based learning opportunity on their sense of appreciation around the importance of social accountability and health advocacy [13]. The opportunity provided second-year medical students the ability to take part in a community-service option as an alternative to classroom-based learning, providing medical students the opportunity to work directly with vulnerable and marginalized segments of the population. Students who were interviewed following their experience with the program reported they developed a deeper insight into the disparities that vulnerable populations experience. 
They learned how marginalization leads to exclusion from meaningful participation in society. Marginalized segments of the population face persistent hardships resulting from discrimination, social stigma, and stereotypes. Armed with a deeper understanding of the lived experience of marginalization, the students learned to establish positive relationships with vulnerable segments of a population and became inspired to engage in sustained efforts to effect positive change through meaningful involvement. The insight the students gained helped to nurture their passion to become actively involved in health advocacy throughout their careers.

\section{Integrating the social medicine network in medical education}

While social accountability and health advocacy are addressed in medical curricula, teaching is largely didactic in nature and disconnected from the lived experiences of vulnerable populations $[16,41]$. In response, the Social Medicine Network Ottawa (SMNO) developed a webbased portal that is simple, convenient, and self-directed, allowing students to access the website whenever necessary, and organize participation in opportunities for trainees based on mutually convenient schedules and interests [2]. Being that this is a volunteer-based portal, which is not associated with any curricular credit, the initiative students take is completely by interest and a genuine commitment to address health disparities. Interested students are provided with the website URL to access the portal. This ensures students are not forced to get involved in initiatives they are not experienced with or passionate about, but instead the platform provides the resources necessary to inspire social responsibility and health advocacy.

Additionally, the nature of the platform allows a multidisciplinary approach and collaboration on issues related to the social determinants of health, which can be accessed on the discussion board. This allows healthcare professionals from different domains (i.e. nurses, physiotherapists, occupational therapists, social workers, et cetera) to stimulate deliberation, brainstorm solutions, and create health advocacy initiatives using an interprofessional approach.

At the University of Ottawa, medical students learn about social accountability and health advocacy through lectures and panels hosted by healthcare providers and community organizers as well as through a mandatory $30 \mathrm{~h}$ community service learning placement. Social accountability is taught through the SIM course.

Society, the Individual and Medicine [42]. The course covers a wide curriculum taught using multiple pedagogies including small group teaching, patient interviews, and self-learning modules [43]. The course faculty are appointed on the Social Accountability Leadership
Committee and report to the director of Social Accountability [43]. As part of a Social Accountability framework, a student-run Social Accountability Student Advisory Committee (SASAC) was also created to give students who are passionate about addressing health inequities an active voice both independently and in collaboration with the Social Accountability Leadership Committee. SASAC students have been involved in different leadership committees, advocating for innovative, hands-on, and community-based health advocacy curriculum.

As a group, the SASAC find that experiential learning, and fostering connections between community organizations, healthcare providers, and healthcare trainees, are critical for operationalizing health advocacy, a concept which was the motivation behind implementing the SMN model [3]. SASAC members are responsible for updating the SMNO website on community-based health advocacy opportunities and promoting the platform to medical students, residents, and undergraduate students interested in health equity. Medical school faculty ensure that the directive is handed over to new SASAC members annually, ensuring initiative sustainability. The faculty supervisor also provides mentorship for students involved in the opportunities offered through SMNO and provides support in instances where students face challenges along the way. Unlike the mandatory community service learning component of the curriculum, medical students are not given credit on their medical student performance record for participation in an SMNO promoted opportunity. However, they are able to include this work on their resume. The aim of the SMNO initiative is to cultivate an intrinsic motivation to address health inequities, and to provide practical learning opportunities to those who seek it because of a deep commitment to health advocacy.

\section{Limitations}

To date, the positive impact of this initiative is based on self-reported data. A comprehensive impact assessment is needed to ascertain the effectiveness of the SMN in helping medical trainees become successful health advocates.

\section{Conclusion}

The Social Medicine Network was founded on the principle that social accountability is essential for anyone working in healthcare. It brings together an interdisciplinary group of healthcare professionals, trainees, and community-based organizations to work together and enhance an understanding of the broad range of social factors affecting health and well-being. This article is written to highlight the innovative method of educating medical trainees using the Social Medicine Network for the often neglected CanMEDS role, the health advocate. 
This framework supplements the already existing didactic curriculum that exists in most medical schools, supplementing it with a more experiential-based learning modality. By creating a Social Medicine Network at every medical training institution, we will be working toward addressing the gaps in developing physicians who are feeling more competent as healthcare advocates.

The "Global Consensus for Social Accountability of Medical Schools", urges ongoing efforts among medical schools to identify increasingly innovative ways of teaching social accountability [44]. Teaching and assessing health advocacy, an essential CanMEDS competency, has proved to be a challenging feat. Nevertheless, the SMN has been successful in engaging trainees to address the social determinants of health and to promote social accountability in practical and sustainable ways. The model has generated interest at other universities in Quebec, Ontario, and Nova Scotia, where SMN chapters will be similarly established.

\section{Additional file}

Additional file 1. These templates illustrate the pre-set emails students on the Social Accountability Student Advisory Committee used to recruit volunteer organizations, physicians, shelters, and research departments to be provide opportunities that could be posted on the Social Medicine Network for students to choose from. The blanks were filled in with information that was relevant to the receiving volunteer organization, physician, shelter, or research department

\section{Abbreviations}

LGBTQ: Lesbians, gays, bisexuals, transgenders, and queer; SASAC: Socia Accountability Student Advisory Committee; SMN: Social Medicine Network; SMNO: Social Medicine Network Ottawa; UBC: University of British Columbia; WHO: World Health Organization

\section{Acknowledgments}

Not applicable.

\section{Authors' contributions}

SB served as a co-leader of the 2018-2019 social accountability student advisor committee, contributing to the launch of the SMNO. SB wrote the first draft of the manuscript, contributed to the revising of the manuscript, participated in meetings where ideas for organizing the content and revising the manuscript were discussed, and delegated tasks for manuscript completion. MJS is co-founder of the Social Medicine Network with Dr. Shafik Dharmasi. He contributed significantly with respect to the planning, writing and review of the manuscript. MJ served as a co-leader of the 2017-2018 social accountability student advisory committee, contributing to the launch of the SMNO; contributed to the writing and revising of the manuscript and participated in meetings where ideas for organizing the content and revising the manuscript were discussed. JWS served as a co-leader of the 2017-2018 social accountability student advisory committee, contributing to the launch of the SMNO; contributed to the writing and revising of the manuscript and participated in meetings where ideas for organizing the content and revising the manuscript were discussed. $\mathrm{MH}$ as Director of Social Accountability promoted the development and maintenance of the SMN in Ottawa, from concept to on line product, while contributing edits to the final manuscript. SD served as faculty mentor, contributing to the original conceptualization and funding of the Social Medicine Network project at the University of British Columbia; revised the manuscript critically for important intellectual content; provided final approval of the version to be submitted for publication; and agrees to be accountable for all aspects of the work, its accuracy and integrity. All authors have read and approved the manuscript.

\section{Funding}

No funding.

\section{Availability of data and materials \\ Not applicable.}

Ethics approval and consent to participate

Not applicable.

\section{Consent for publication}

Not applicable.

\section{Competing interests}

The authors declare that they have no competing interests.

\section{Author details}

${ }^{1}$ Faculty of Medicine, University of Ottawa, Ottawa, Ontario, Canada. ${ }^{2}$ Department of Surgery, University of Ottawa, Ottawa, Ontario, Canada. ${ }^{3}$ College of Health Sciences, The University of Texas at El Paso, El Paso, TX, USA.

Received: 22 September 2019 Accepted: 16 January 2020

Published online: 30 January 2020

\section{References}

1. Poulton A, Rose $\mathrm{H}$. The importance of health advocacy in Canadian postgraduate medical education: current attitudes and issues [Internet]. Canadian medical education journal. University of Calgary, Health Sciences Centre; 2015 [cited 2019Aug30]. Available from: https://www.ncbi.nlm.nih. gov/pmc/articles/PMC4795083/

2. Hubinette $M$, Ajjawi $R$, Dharamsi S. Family physician preceptors' conceptualizations of health advocacy: implications for medical education. Acad Med. 2014;89(11):1-8.

3. Dharamsi S, Ho A, Spadafora SM, Woollard R. The physician as health advocate: translating the quest for social responsibility into medical education and practice. Acad Med. 2011;86(9):1108-13.

4. Mu L, Shroff F, Dharamsi S. Inspiring Health Advocacy in Family Medicine: A Qualitative Study. Educ Health 11 (online). 2011;24(1):534.

5. Luft LM. The essential role of physician as advocate: how and why we pass it on. Can Med Educ J. 2017:8(3):e109-16.

6. Bhate TD, Loh LC. Building a Generation of Physician Advocates: The Case for Including Mandatory Training in Advocacy in Canadian Medical School Curricula. Acad Med. 2015;90(12):1602-6.

7. Law M, Leung P, Veinot P, Miller D, Mylopoulos M. A Qualitative Study of the Experiences and Factors That Led Physicians to Be Lifelong Health Advocates. Acad Med. 2016;91(10):1392-7.

8. Jilg S, Möltner A, Berberat P, Fischer MR, Breckwoldt J. How do supervising clinicians of a university hospital and associated teaching hospitals rate the relevance of the key competencies within the CanMEDS roles framework in respect to teaching in clinical clerkships? GMS Zeitschrift fur medizinische Ausbildung. 2015;32(3):Doc33. https://doi.org/10.3205/zma000975 https:// www.ncbi.nlm.nih.gov/pmc/articles/PMC4580442/.

9. Stutsky BJ, Singer $M$, Renaud R. Determining the weighting and relative importance of CanMEDS roles and competencies. BMC Res Notes. 2012;5(1): 354.

10. Rademakers JJDJM, De Rooy N, Ten Cate OTJ. Senior medical students' appraisal of canMEDs competencies. Med Educ. 2007:41(10):990.

11. Dharamsi S, Richards M, Louie D, Murray D, Berland A, Whitfield M, et al. Enhancing medical students' conceptions of the CanMEDS health advocate role through international service-learning and critical reflection: a phenomenological study. Med Teach. 2010;32(12):977-82.13.

12. Verma S, Flynn L, Seguin R. Faculty's and residents' perceptions of teaching and evaluating the role of health advocate: a study at one Canadian university. Acad Med. 2005:80(1):103-8.

13. Roughead T, Hill H, Dewar K, Kasteel N, Hamilton K. The need for social accountability in medical school education: a tale of five students' integration into Vancouver's Downtown Eastside. University of Ottawa 
Medicine Journal, 2017 Jan; 1-3. Available from: https://uottawa. scholarsportal.info/ojs/index.php/uojm-jmuo/article/view/1512

14. Strasser R, Worley P, Strasser S. Chapter 31. LICS, community-engaged education, and social accountibility. In: Alliance for Clinical Education, editor. Longitudinal Integrated Clerkship: Principles, Outcomes, Practical Tools: Gegansatz Press; 2016. [cited 2019 Apr 4].

15. Ventres W, Dharamsi S. Socially Accountable Medical Education-The REVOLUTIONS Framework. Acad Med. 2015:90(12):1728.

16. Dharamsi S, Espinoza N, Cramer C, Amin M, Bainbridge L, Poole G. Nurturing social responsibility through community service-learning: Lessons learned from a pilot project. Med Teach. 2010;32(11):905-11.

17. Bainbridge L, Grossman S, Dharamsi S, Porter J, Wood V. Engagement studios: students and communities working to address the determinants of health. Educ Health (Abingdon). 2014;27(1):78-82.

18. Ventres W, Kravitz JD, Dharamsi S. PEARLS+: Connecting Societal Forces, Social Determinants, and Health Outcomes. Acad Med. 2018 Jan;93(1):143.

19. Haq C, Grosch M, Carufel-Wert D. Leadership opportunities with communities, the medically underserved, and special populations (LOCUS). Acad Med. 2002:77:740.

20. Hancher-Rauch HL, Gebru Y, Carson A. Health advocacy for busy professionals: effective advocacy with little time. Health Promot Pract. 2019 Jul;20(4):489-93

21. Strasser R, Worley P, Cristobal F, Marsh DC, Berry S, Strasser S, Ellaway R. Putting communities in the driver's seat: the realities of communityengaged medical education. Acad Med. 2015;90(11):1466-70.

22. The Social Medicine Network BC (SMBC) [Internet]. The University of British Columbia: Faculty of Medicine Global Health; 2014 Mar 31 [cited 2019 Apr 20];[about 1 screen]. Available from: https://globalhealth.med.ubc.ca/thesocial-medicine-network-bc-smbc/

23. Sklar DP. Why effective health advocacy is so important today. Acad Med. 2016;91(10):1325-8.

24. Archer $\mathrm{D}$. The community health advocacy program: changing the relations between communities and the medical campus. Med Health R I. 1996:79:420-1.

25. Burrows MS, Chauvin S, Lazarus CJ, Chehardy P. Required service learning for medical students: program description and student response. Teach Learn Med. 1999;11:223-31.

26. Cham PM. Enhancing cultural education through service learning: a medical student's perspective. WMJ. 2004;103:13-4

27. Patricoski C. Community diagnosis by summer externs in rural West Virginia. Fam Community Health. 1997;20:60-9.

28. Olney CA, Livingston JE, Fisch S, Talamantes MA. Becoming better health care providers: outcomes of a primary care service-learning project in medical school. J Prev Interv Community. 2006;32:133-47.

29. Olm-Shipman C, Reed V, Christian JG. Teaching children about health, part II: the effect of an academic-community partnership on medical students' communication skills. Educ Health. 2003;16:339-47.

30. Elam CL, Musick DW, Sauer MJ, Skelton J. How we implemented a servicelearning elective. Med Teach. 2002;24:249-53.

31. Fournier A. Health fairs as a unique teaching methodology. Teach Learn Med. 1999:11:48-51.

32. Elam CL, Sauer MJ, Stratton TD, Skelton J, Crocker D, Musick DW. Service learning in the medical curriculum: developing and evaluating an elective experience. Teach Learn Med. 2003;15:194-203.

33. Clark DL, Melillo A, Wallace D, Pierrel S, Buck DS. A multidisciplinary, learnercentered, student-run clinic for the homeless. Fam Med. 2003;35:394-7.

34. Powers CA, Thomson CC, Feuerstein I, et al. Smoking sleuths: a pilot tobacco prevention elective for medical school students. J Cancer Educ. 2008;23:122-5

35. Vogel A, Seifer S. Impacts of sustained institutional participation in servicelearning. Int J Commun Res Engagement. 2011;4:186-202.

36. Earnest MA, Wong SL, Federico SG. Perspective: physician advocacy: what is it and how do we do it? Acad Med. 2010;85(1):63-7.

37. Shah SI, Brumberg HL. Advocating for advocacy in pediatrics: supporting lifelong career trajectories. Pediatrics. 2014;134(6):e1523-7.

38. Schwarz K, Sisk B, Schreiber J, Malik F. A common thread: pediatric advocacy training. Pediatrics. 2015;135(1):7.

39. Mezirow J. Transformative dimensions of adult learning: ERIC; 1991.

40. Hakim J, Black A, Gruslin A, Fleming N. Are Canadian postgraduate training programs meeting the health advocacy needs of obstetrics and gynaecology residents? J Obstet Gynaecol Can. 2013;35(6):539-46.
41. Hirsh D, Worley P. Better learning, better doctors, better community: how transforming clinical education can help repair society. Med Educ. 2013; 47(9):942-9.

42. University of Ottawa, Faculty of Medicine. Social, the Individual, and Medicine. https://curriculum.med.uottawa.ca/eng/SIM/data/SIM_ Introduction_2016_e.html.

43. University of Ottawa, Faculty of Medicine. Society, the Individual, and Medicine. https://globalhealth.med.ubc.ca/the-social-medicine-network-bcsmbc/

44. Global Consensus for Social Accountability of Medical Schools [Internet] 2010 Dec [cited 2019 Apr 20]. Available from: https:// healthsocialaccountability.sites.olt.ubc.ca/files/2011/06/11-06-07-GCSAEnglish-pdf-style.pdf

\section{Publisher's Note}

Springer Nature remains neutral with regard to jurisdictional claims in published maps and institutional affiliations.
Ready to submit your research? Choose BMC and benefit from:

- fast, convenient online submission

- thorough peer review by experienced researchers in your field

- rapid publication on acceptance

- support for research data, including large and complex data types

- gold Open Access which fosters wider collaboration and increased citations

- maximum visibility for your research: over $100 \mathrm{M}$ website views per year

At BMC, research is always in progress.

Learn more biomedcentral.com/submissions 